\title{
Motivation, Interaction, and Teaching Strategy of the Teachers Dealing with Autism Spectrum Disorder Children
}

Rati Kapoor ( $\sim$ kapoor9961@gmail.com )

The INCLEN Trust International https://orcid.org/0000-0003-3164-715X

Arpit Singh

ICMR - National Institute of Cancer Prevention and Research https://orcid.org/0000-0001-6742-0876

Manas Ranjan Pradhan

International Institute for Population Sciences

\section{Research Article}

Keywords: Autism Spectrum Disorders, Teaching strategy, Motivation, Impact on teachers, India

Posted Date: January 25th, 2021

DOl: https://doi.org/10.21203/rs.3.rs-151678/v1

License: (c) (i) This work is licensed under a Creative Commons Attribution 4.0 International License.

Read Full License 


\section{Title of the Study:}

Motivation, Interaction, and Teaching Strategy of the Teachers Dealing with Autism Spectrum Disorder Children

\section{Authors Details:}

1) Ms. Rati Kapoor

Research Officer,

The INCLEN Trust International, New Delhi, India

Email Id - kapoor9961@gmail.com

2) Mr. Arpit Singh

Project Manager

WHO FCTC Global Knowledge Hub on Smokeless Tobacco

ICMR-National Institute of Cancer Prevention and Research, Noida, India

Email Id - singh.arpit.lko@gmail.com

3) Dr. Manas Ranjan Pradhan

Assistant Professor

Department of Fertility Studies

International Institute for Population Sciences, Govandi East, Mumbai, India

Email Id-manasiips@gmail.com

\section{*Address for Correspondence}

Ms. Rati Kapoor

Research Officer

The INCLEN Trust International,

Okhla Industrial Phase 1, New Delhi, 110020

Email Id - Kapoor9961@gmail.com

Keywords: Autism Spectrum Disorders, Teaching strategy, Motivation, Impact on teachers, India.

Conflict of Interest: None 


\title{
Motivation, Interaction, and Teaching Strategy of the Teachers Dealing with Autism Spectrum Disorder Children
}

\begin{abstract}
:
Caregivers such as teachers and parents have a huge impact on children with Autism Spectrum Disorder (ASD). 10 in-depth semi-structured interviews with teachers explored motivation, interaction and teaching strategy among teachers dealing with children with Autism. Study showed that the teachers lack in-depth knowledge or practice session or course regarding Autism despite their education. With work experience as teacher or therapist they gain insight on Autism. Study found some unique ways of interaction among teachers and children such as sign language and picture method. Also, no specific teaching strategy was used, as every teacher uses different strategy for different child. Further research is required for deep awareness and teaching development programmes so that they can help children with Autism.
\end{abstract}




\section{Motivation, Interaction, and Teaching Strategy of the Teachers Dealing with Autism Spectrum Disorder Children}

\section{Introduction}

Autism Spectrum Disorder (ASD) is a neurological and developmental disorder that begins early in childhood and lasts throughout a person's life (ICD 10). It affects how a person acts and interacts with others, communicates, and learns. Caregivers such as teachers and parents have a huge impact on children with ASD. As the prevalence of autism is increasing, every ordinary school teacher is likely to serve autistic children (McMahon, Stoll, \& Linthicum, 2020). However, many teachers lack sufficient awareness, knowledge, and understanding of Autism to meet the needs of these students in ordinary schools. A dissertation by (Hendricks, 2007) evaluated specialised teachers' knowledge and implementation of educational practices is critical for the improvement of children with Autism. Also, children with ASD often have difficulty in understanding or communicating their needs to teachers and classmates. They also have challenges in following some classroom instruction, along with the subtle vocal and facial cues of teachers (Bowe, 2005; Wilmshurst \& Brue,.). Little research has evaluated the qualities of teachers for children with Autism. It is verified that the learning characteristics of these individuals differ widely from other learners requiring teachers to possess specialised skills. (Simpson, 2005).

Studies found that teachers held incorrect convictions about students with Autism, particularly in the area of cognition, when compared to Autism specialists (Stone \& Rosenbaum, 1988). Furthermore, studies have shown that therapist have received insufficient knowledge of professional, academic and clinical training in ASD despite their education (Cascella \& Colella, 2004). General teachers need more inclusive training than specialised teachers. Moreover, specialised teachers expressed greater confidence in performing inclusion related tasks such as adapting curriculum, participating in IEP (Individualized Education Programmes) 
meetings, and writing behavioural objectives. Previous study showed specialised professionals has higher knowledge about ASD (Hayat et al., 2019).

Further research is required to determine whether teachers possess knowledge of educational practices, whether they implement the practices into the classroom and, they had received proper training which are crucial for children with Autism. The purpose of this study focused on teachers who serve students with autism to identify characteristics as well as specific knowledge and practices of teachers who work with this population.

\section{Method}

A qualitative study was conducted in two specialised schools in Mumbai. The teachers were interviewed thoroughly about their motivation, interaction, and teaching strategy with autistic children. A total of 10 teachers were ready for the interview. The mean age of teachers interviewed was 26 years and their mean years of experience were found to be 4 years. Most of the teachers studied Psychology as a subject during their course. One out of 10 was male in this study.

The 10 in-depth semi-structured interviews with teachers explored themes such as motivation, interaction, and teaching strategy. The questions were open-ended, and we explored the teachers' experience. Each interview was conducted by two investigators, one as a lead interviewer and the other as a note taker in a single sitting lasting 40-60 minutes with audio recording. The language used was according to the participant's preference viz., English or Hindi

The recorded interviews were transcribed. The transcriptions were done by the first author and the second author. These transcriptions were verified by the third author for correctness and completeness. Figure 1 shows the complete analytical process. Nvivo 10 was used for organizing and coding data (Castleberry, 2014). Codes from the data were identified and 
defined iteratively. We started with open coding of the 'meaning units' followed by the axial coding. The purpose of axial coding was to begin the process of reassembling data that were fractured during open coding. In axial coding, categories were related to their subcategories to form more precise and complete explanations about phenomena under the study. After theoretical saturation, selective coding process was followed to integrate and refine categories. The relationship between emerging themes, categories, and codes were studied using memos, graphic representations, and conceptual frameworks through an iterative process. Anonymous direct quotes were used as examples of particular themes to substantiate the findings, where appropriate.

Informed Consent: "Informed consent was obtained from all individual participants included in the study."

\section{Results}

The study showed how the teachers were affected, grow, interact, stay motivated, and teach children with Autism. The phenomenology of the teacher's experience had been described in a conceptual framework (Figure 2). Figure 3 showed where and how the teachers were being focused while giving their interviews with the researcher. The researcher utilised several visualisations to help explore the words most frequently used by teacher participants and to view source data by areas of coding similarities. As in the figure word frequency count documented over 1000 instances of the term "child", because they talked about the experience of the child, their problems, behaviour, and understanding skills. Other words that were heavily weighted in the frequency count included (in order of frequency): autism, think, different, something, understand, parents, special, teaching, experience as the word "child" was central to the reasons that participants talk about. 


\section{The way teacher describes Autism:}

One word for Autism as per the teacher's perspective was mainly found to be unique and different. According to them, each child was different, and each child had some or the other unique ability which distinguishes each child.

The quote from the respondent:

"Just in word... Unique. Because every child on the spectrum is unique. You will never see the same features and same characteristics in all the child on the spectrum

Two of the respondents described autism as 'mysterious' and 'consistent' because to be with the child they need to be consistent with their behaviour, reaction and, teaching to help them overcome their problems. The respondents are also always curious about the child and his/her behaviour. Also, the respondents want to know the child in their way.

The quote from the respondent is:

"This is quite difficult; would say "consistency or mysterious". Because you have to be consistent with your words, regarding your behaviour, reaction and teaching method. Consistency had helped a lot with a lot of the kids we are working with."

\section{Knowledge:}

In this study, an equal proportion of the teachers had a master's or bachelor's degree in psychology or they also had a Bachelor of Education in special needs. Teachers were not fully aware regarding autism. Only two respondents had taken some training such as Masgutova Neurosensorimotor Reflex Integration SM (MNRI $\left.{ }^{\circledR}\right)$, Rhythmic Movement Training (RMT), special training for teachers, and tapping to help children with autism.

The quote stating this respondent:

"I have many professional training like MNRI, RMT and tapping, but these are the international courses." 
The study showed that teachers do not have the proper theoretical and practical knowledge of children with autism. The major knowledge-based learning is only through what they see and what they learn while being with children either in a hospital or therapy centre. Only a few receive proper training, but that too in special schools which is very limited.

\section{Motivation:}

The study did not find any specific motivation among teachers for choosing teaching as their profession. Teachers got motivated or inspired during their jobs or internship when they had an incident with children who were in spectrum. The study found multiple life incidents, that inspired these teachers to be in this profession.

To quote a respondent:

“When I was teaching Music, I came across a student who was having autism. I did not know anything about autism, and after that, I started researching it"'

To quote another respondent:

"I thought of doing Physiotherapy instead of MBBS. When I started the course, I got to know more about the children with autism. I wanted to help them and do something for them".

There was another story of one who did not want to be in this profession but then gets into this profession because one event eventually touched him/her the heart and he/she believed that he/she could make changes in ASD child's life.

To quote a respondent:

"I want to become actor earlier but due to lack of money people suggested me to go for teaching. With teaching I have changed as a person and kids were enjoying my class. Even, I was really enjoying it"'. 


\section{Instrumental Methods:}

The study found multiple instrumental methods used by teachers such as picture exchange communication method, TEACCH (Teaching, Expanding, Appreciating, Collaborating and Cooperating, Holistic) method, Text method, Verbal behaviour method. Teachers were not using any kind of special techniques which help the children like Applied Behaviour Analysis (ABA), Discrete Trial Teaching (DTT), and Pivotal Response Treatment (PRT). Teachers knew about these methods but they were not using it as these require a high set of instruction for children.

The Quote mentioning this is -

"Yes. ABA \& pictures but not verbal behaviour. I do not use these programs in an absolute sense, but I use some elements of it which I think that might work. These are very structured programs which are not easily adopted by anyone like VB and ABA. I mainly used Picture exchange communication system."

Some teachers used the above techniques but they were not aware of the actual scientific name. On further interviewing we found that some had listened about these techniques through their acronyms and they were using it by those names only. Teachers were also using multiple other techniques such as Action Behaviour Consequence (ABC), Therapeutic Listening RMD, and behaviour and speech-based techniques.

The quote stating this is -

"Actually we have just done ABA. Yes, I have heard about it. As an occupational therapist I am not using many of these things. We are using more of other therapies 
like we have therapeutic listening RMD these are all occupational. The behavioural therapist uses more of that".

The study found two teachers who used only one type of instrumental method and they did not know about any other method.

The quote of two respondents are-

Respondent 1:

"No, I have not heard about these methods, sometimes we use sign language."

Respondent 2:

"Yes, I know ABA, but I do not know any other methods."

This study showed that some teachers were not sure of these methods which were used worldwide. However, they think that each child was unique and each child needs a different type of care and interaction method which cannot be perceived through these methods only.

\section{The strategy used to interact with ASD children:}

Teachers often found it essential to work with parents to help build an inclusive learning environment for students. In creating an inclusive environment, ten of the teachers described how it is essential to build a repo with the student and parents as well as to had an open system of communication. Teachers discussed the importance of building a warm and caring relationship with the child, so they felt comfortable within the class.

The study showed us that there were multiple unique ways through which teachers interact with children with ASD such as sign language, picture communication to understand the needs of the children. In one of the schools, there was one teacher who was specially assigned to 
understand each child individually and from the investigator's point of view, this would help children in their development.

\section{Teaching Strategy:}

This study did not find any particular type of teaching strategy for children with autism as every teacher uses a different strategy. Some used clay as children did not had proper grip in their hands; some used computers or laptops to write and learn. Teachers in both schools were using conventional techniques for the children to make them learn. On observation, when a teacher needs to seek attention, they used either count numbers "1...2...3.. look at me", or they used to clap three times.

The quote from the respondent is -

"There is no one size fit approach. Every child will react differently so to any therapy that he receives so it may work or not.

According to teachers, drama techniques were also useful as they help in emotional development for the children. This technique consists of short drama for the children of about 1 - 2 minutes with simple emotional responses such as crying, laughing, many more.

In this study, we found out that the atmosphere in specialised schools was different; they don't have the same syllabus, no pressure of homework and exams. In these specialised schools they learn to work upto their skills so that they can stood up and thrive in the society. The specialised schools had multiple learning materials in walls and classrooms. These materials includes pictures of $\mathrm{ABCD}$...Z, mathematical tables, numbers, and science related figures such as solar system, periodic table. In classrooms, there were multiple teachers who act as shadow teachers to look after children while the main teacher was deliberating knowledge. There were other 
things also which got included in classroom adjustment which was using technology as many children have sensory issues such as touch. The technological interventions which were given include laptops and tablets but teachers believe that writing is essential for their motor development so they also used clay and other soft materials to draw thing and learn.

\section{Learning:}

Patience was one of the main quality which was found in teachers. Patience was highly needed which helped children to get comfortable with the teacher, they need to understand the teacher, and they have to allow teachers in their world which takes time and a great amount of patience.

The quote stating this is:

"Lots of things, I think, patience, how to be positive, I learn how to be happy in smallest things, by which your patience's increase and if we gave them love, they will give you all love."

Some teacher also said they learned to be positive. In teacher's perspective, showing to the world that what you want or what we were trying to do, is not a bad thing. We must have the courage to show that in which aspect we were good and what we can do; In other words, we can say that we should be able to show the world who we are.

The quote from the respondent stating this is:

"Don't be afraid to show the world that WHO YOU ARE" 
One of the respondents learned that it is ok to fail. With these children, they always learned how to improve as they used to fail many times as each child was different. With each child, no standard method can be applied so they had to develop things that can help the child. So improving with failure also helped them in daily life.

The quote from the respondent is:

"In life you should believe that it is okay to fail and it is just fear of the head, and now you can literally try to do anything. Sometimes I'm scared and nervous for a while, When I try something new, but it's fine if I fail. I tell myself "fast fail or cheap fails" atleast, I should to try."

In view to all respondents, the major learning was how to be patient, stay positive and improve at each step of our life with children in spectrum.

\section{Discussion}

The study found teachers had multiple ways of interaction like parallel talk, sign language, picture methods but the awareness regarding autism was less among them. Dealing with ASD children teachers had impact on their life, they got motivated and they learned positive approach for life.

Results have shown that teachers have been motivated to work and understand Autistic children from their post-graduation studies or their exposure to these children. Also, study conducted among Chinese primary school teachers have shown that knowledge, teacher's positive attitude, self-image, and motivation have helped the children with special needs. The study also showed that teacher's professional self-efficacy also enhances in correlation with attitude and knowledge while working with children with ASD (Lu et al., 2020). 
Professional development and training of educator's is of utmost importance in dealing with nature and needs of children with ASD. Different factors such as teachers' education level, experience, and contact with ASD children were found to have a significant direct effect on the level of teacher's knowledge about Autism (Arif, Niazy, Hassan, \& Ahmed, 2013). In our study, we found that since the teachers have the background of psychology and B.Ed. in special needs, that they at least know about Autism but they do not have any kind of in-depth knowledge or practice session or course with which they can learn about Autism. They have learned about autism from their work experience as a teacher or therapist in a special school or centres/hospitals.

Studies have shown that school teachers must be aware of Autism (Petersson Bloom, 2020). Awareness of Autism is the first step in supporting and serving students with Autism. Teachers need to learn about the nature of Autism and the needs of children with Autism (Haimour \& Obaidat, 2013; Lu et al., 2020). A study done in Pakistan showed that out of 170 teachers purposively selected from public and private schools only 94 (55\%) of the teachers know about autism through media, 15 (9\%) had training through workshops and $105(62 \%)$ have the opinion that Autism is treatable (Arif et al., 2013). A study conducted in Ireland showed similar results that teachers don't have an adequate level of knowledge regarding Autism (Young, Mannix McNamara, \& Coughlan, 2017). Similarly, previous studies suggested that many teachers lack basic knowledge about ASD (Alexander, Ayres, \& Smith, 2015; Allday, NeilsenGatti, \& Hudson, 2013; Barnhill, Sumutka, Polloway, \& Lee, 2014; Petersson Bloom, 2020). Also previous studies revealed that attitudes regarding ASD awareness in preschool professionals had changed after completing a professional development programme, and they believed that the professional development programme had an influence on their practice. These results indicate that the professional development programme, can serve as a starting point for enhancing ASD awareness and accommodation amongst preschool professionals 
(Petersson Bloom, 2020). Results from our study and these studies clearly shows that there is a dire need for raising awareness and provide the basic training, knowledge and professional development programs among teachers.

The study showed that teachers used different teaching techniques such as picture method, TEACCH method, they were not using other international methods which includes ABA, DRT and PRT. A study showed that there is need to increase awareness among educators regarding methods for improving the learning context, and thereby changing their practice to create a more inclusive setting for children with ASD (Petersson Bloom, 2020).

One of the other scenarios found in our study is that all of the teachers have a view that each child is unique or mysterious in its own way so there is no one method with which teachers can help the child so using a worldwide set method for the child will not help the child. The study conducted in the Pune district of Maharashtra state of India have described AUTISM as Always Unique Totally Interesting Sometimes Mysterious (Upendra, 2013).

A study conducted by Azad et.al. tried to build up an intervention model to improve communication of parents and teachers with children of ASD. The intervention model so formed was not the same for all the children rather it was more specific to each child itself as it was based on the outcome of the children which was unique in itself (Azad, Marcus, Sheridan, \& Mandell, 2018). In our study teachers used different methods such as parallel talk, picture method, sign language to communicate with the children.

\section{Strengths and Limitations:}

The strengths of this study are that it is the first in-depth attempt to understand both teachers' perspectives on the characteristics of children with ASD and perceived risk factors in Indian settings. Moreover, the findings highlight teachers' knowledge, attitude, behaviour, and learning with children of Autism which contributes to existing literature. 
The limitations of this study are equally worth mentioning. Like other qualitative studies, our findings are based on a purposively selected sample and setting, compelling us to be careful while generalising the results.

The findings suggest there is dire need for policy and program to improve the awareness of ASD. Further research is required firstly, to investigate what training method can be used for teachers, secondly, early diagnosis of ASD which can help in improving the outcome for children with ASD. As in Saudi Arabia, there is the availability of services like non-medical, biomedical, and religious treatment for children with ASD (Alnemary, Aldhalaan, SimonCereijido, \& Alnemary, 2017), there is an immense need for such services in other developing countries too. 


\section{References:}

Alexander, J. L., Ayres, K. M., \& Smith, K. A. (2015). Training Teachers in Evidence-Based Practice for Individuals With Autism Spectrum Disorder. Teacher Education and Special Education: The Journal of the Teacher Education Division of the Council for Exceptional Children, 38(1), 13-27. https://doi.org/10.1177/0888406414544551

Allday, R. A., Neilsen-Gatti, S., \& Hudson, T. M. (2013). Preparation for Inclusion in Teacher Education Pre-Service Curricula. Teacher Education and Special Education: The Journal of the Teacher Education Division of the Council for Exceptional Children, 36(4), 298311. https://doi.org/10.1177/0888406413497485

Alnemary, F. M., Aldhalaan, H. M., Simon-Cereijido, G., \& Alnemary, F. M. (2017). Services for children with autism in the Kingdom of Saudi Arabia. Autism, 21(5), 592-602. https://doi.org/10.1177/1362361316664868

Arif, M. M., Niazy, A., Hassan, B., \& Ahmed, F. (2013). Awareness of Autism in Primary School Teachers. Autism Research and Treatment, 2013. https://doi.org/10.1155/2013/961595

Azad, G. F., Marcus, S. C., Sheridan, S. M., \& Mandell, D. S. (2018). Partners in School: An Innovative Parent-Teacher Consultation Model for Children with Autism Spectrum Disorder. Journal of Educational and Psychological Consultation, 28(4), 460-486. https://doi.org/10.1080/10474412.2018.1431550

Barnhill, G. P., Sumutka, B., Polloway, E. A., \& Lee, E. (2014). Personnel Preparation Practices in ASD. Focus on Autism and Other Developmental Disabilities, 29(1), 39-49. https://doi.org/10.1177/1088357612475294

Cascella, P. W., \& Colella, C. S. (2004). Knowledge of Autism Spectrum Disorders Among Connecticut School Speech-Language Pathologists. Focus on Autism and Other Developmental Disabilities, 19(4), 245-252. https://doi.org/10.1177/10883576040190040601

Castleberry, A. (2014). NVivo 10 [software program]. Version 10. QSR International; 2012. American Journal of Pharmaceutical Education, 78(1), 25. https://doi.org/10.5688/ajpe78125

Frank, B. (2005). Making Inclusion Work. In Pearson/Merrill/Prentice Hall. Retrieved from https://books.google.co.in/books/about/Making_Inclusion_Work.html?hl=sv\&id=cxKAAAAYAAJ\&redir_esc=y

Haimour, A. I., \& Obaidat, Y. F. (2013). School Teachers' Knowledge about Autism in Saudi Arabia. World Journal of Education, 3(5), 45. https://doi.org/10.5430/wje.v3n5p45

Hayat, A. A., Meny, A. H., Salahuddin, N., M Alnemary, F., Ahuja, K.-R., \& Azeem, M. W. (2019). Assessment of knowledge about childhood autism spectrum disorder among healthcare workers in Makkah- Saudi Arabia. Pakistan Journal of Medical Sciences, 35(4), 951-957. https://doi.org/10.12669/pjms.35.4.605

Hendricks, D. R. (2007). A Descriptive Study of Special Education Teachers Serving A Descriptive Study of Special Education Teachers Serving Students with Autism: Knowledge, Practices Employed, and Students with Autism: Knowledge, Practices Employed, and Training Needs Training Needs Downloaded from Downloaded from. In Theses and Dissertations. https://doi.org/https://doi.org/10.25772/CXC7-XE22 
ICD 10. (n.d.). Retrieved July 8, 2020, from http://priory.com/psych/icd.htm

Lu, M., Zou, Y., Chen, X., Chen, J., He, W., \& Pang, F. (2020). Knowledge, attitude and professional self-efficacy of Chinese mainstream primary school teachers regarding children with autism spectrum disorder. Research in Autism Spectrum Disorders, 72, 101513. https://doi.org/10.1016/j.rasd.2020.101513

McMahon, C. M., Stoll, B., \& Linthicum, M. (2020). Perceived versus actual autism knowledge in the general population. Research in Autism Spectrum Disorders, 71. https://doi.org/10.1016/j.rasd.2019.101499

Petersson Bloom, L. (2020). Professional Development for Enhancing Autism Spectrum Disorder Awareness in Preschool Professionals. Journal of Autism and Developmental Disorders. https://doi.org/10.1007/s10803-020-04562-9

Simpson, R. L. (2005). Evidence-Based Practices and Students With Autism Spectrum Disorders. Focus on Autism and Other Developmental Disabilities, 20(3), 140-149. https://doi.org/10.1177/10883576050200030201

Stone, W. L., \& Rosenbaum, J. L. (1988). A comparison of teacher and parent views of autism. Journal of Autism and Developmental Disorders, 18(3), 403-414. https://doi.org/10.1007/BF02212195

Upendra, M. S. (2013). Knowledge of Autism Among Pre School Teachers. In Sinhgad e Journal of Nursing.

Wilmshurst, L., \& Brue, A. W. (2010). The Complete Guide to Special Education Special Education Expert Advice on Evaluations, IEPs, and Helping Kids Succeed. Retrieved from www.josseybass.com

Young, K., Mannix McNamara, P., \& Coughlan, B. (2017). Post-primary school teachers' knowledge and understanding of autism spectrum disorders. Irish Educational Studies, 36(3), 399-422. https://doi.org/10.1080/03323315.2017.1350594 
Figure 1: Analytical Process

In Depth Interview of teachers

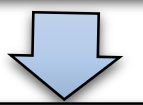

Translated into English

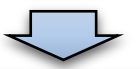

Collaborated by notes taken during Interview

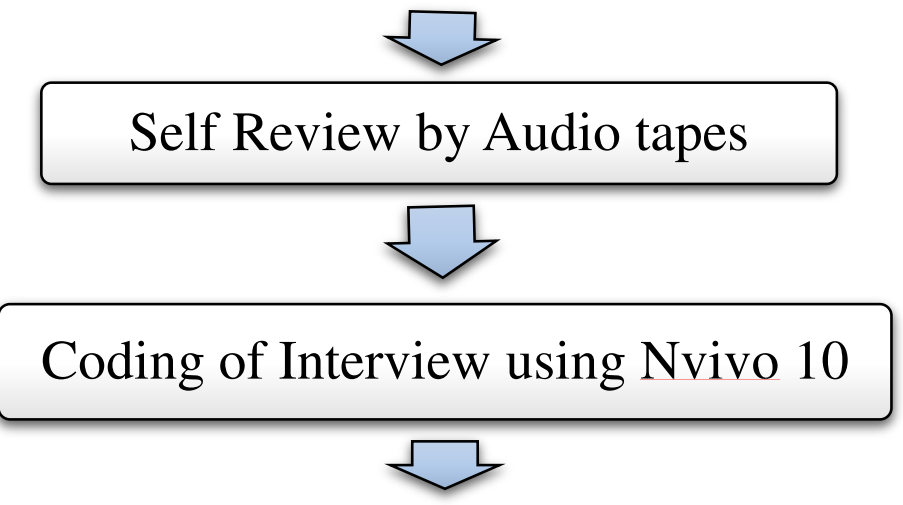

Initial Themes(Impact over teachers, Interaction of Kid with teachers.)

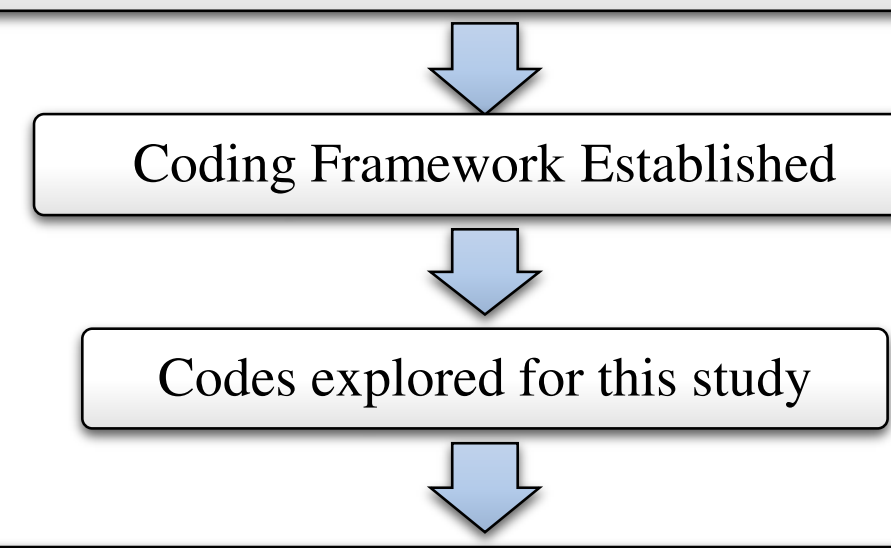

Motivation, interaction and teaching strategy of the teachers 
Figure2: ASD- Teacher's Perspective
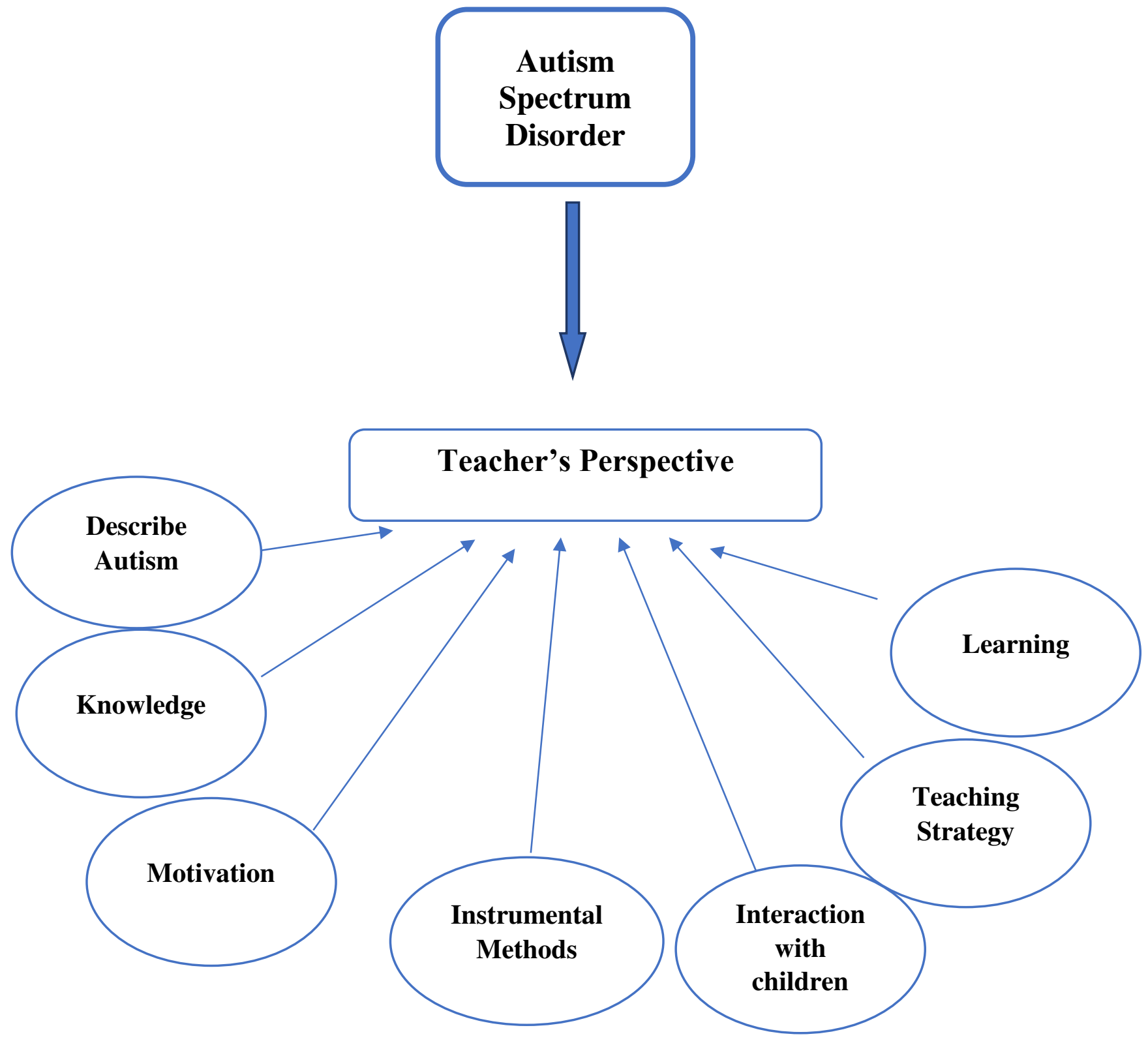
Figure 3: Word Cloud: Teacher's Perspective

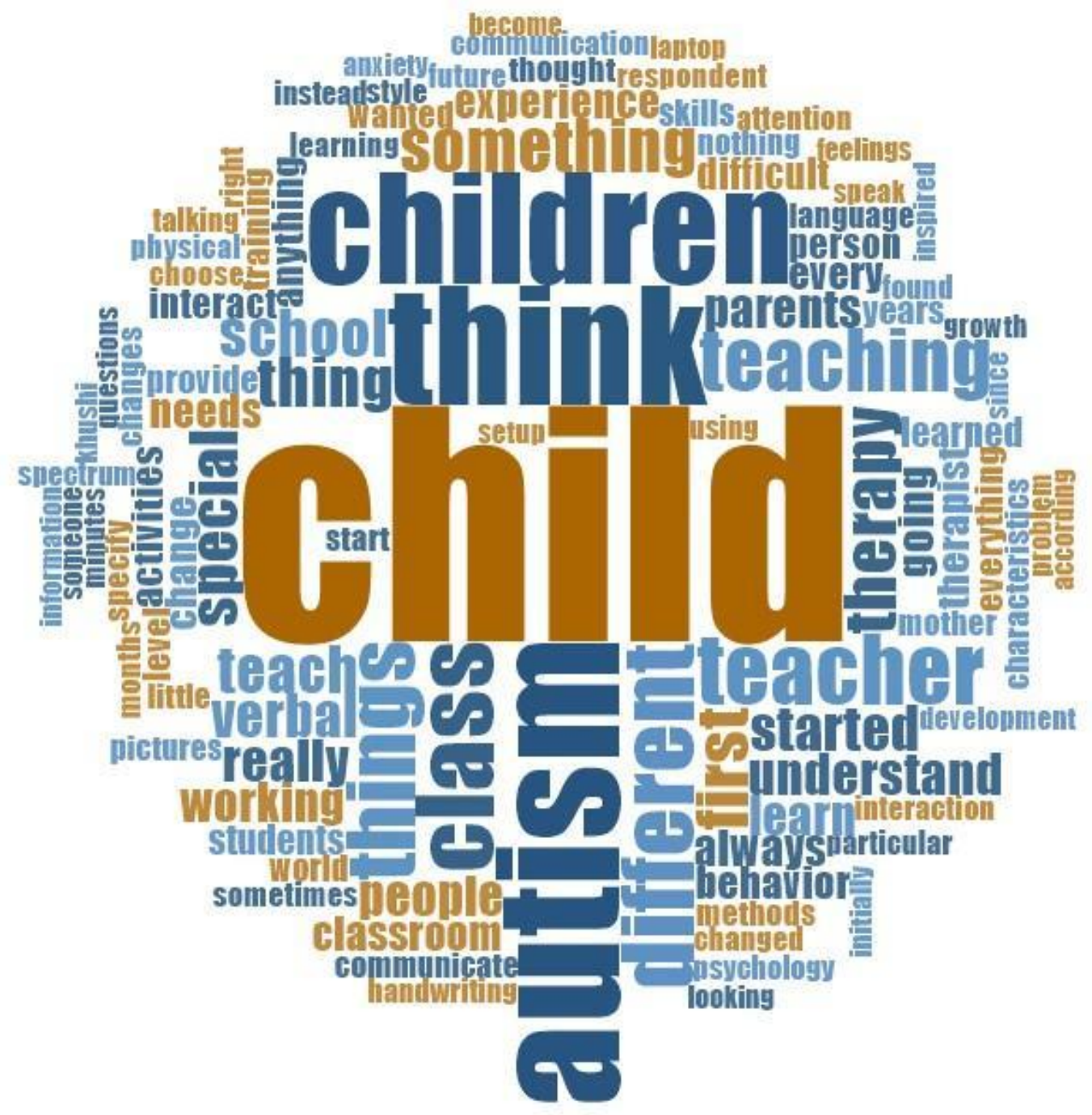


Figures
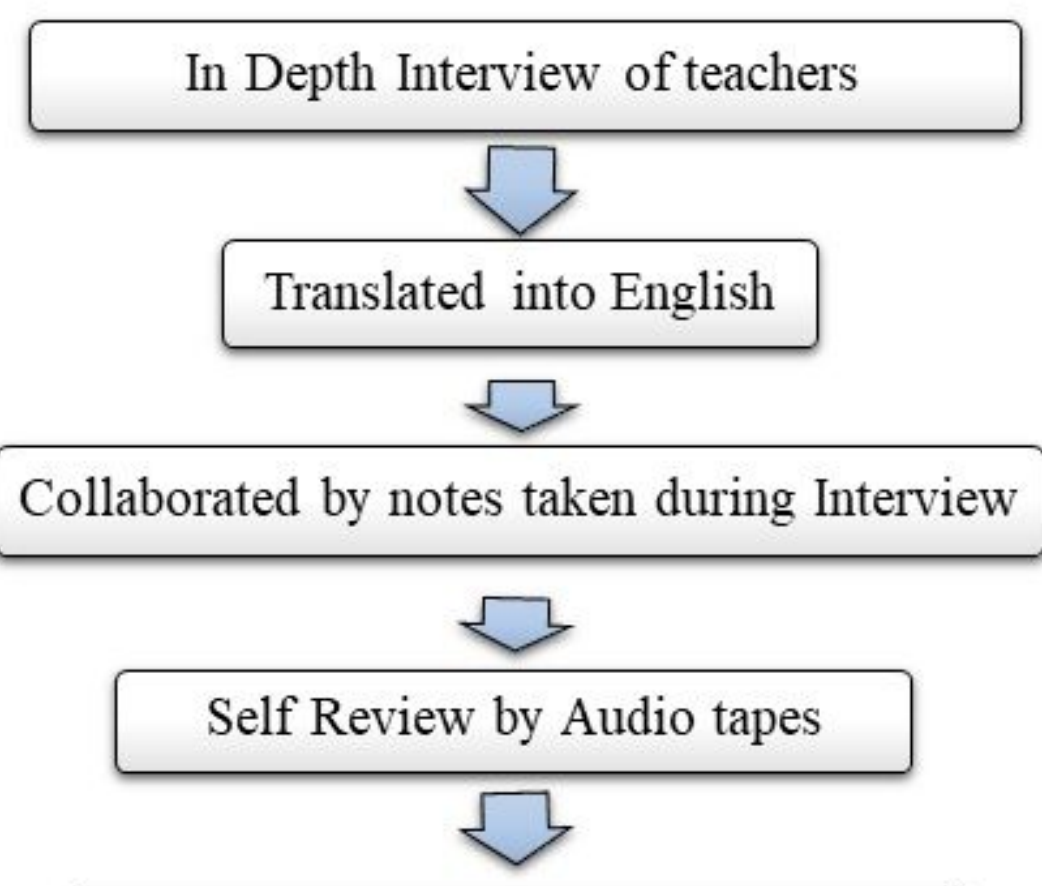

Coding of Interview using Nvivo 10

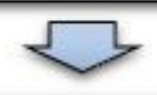

Initial Themes(Impact over teachers, Interaction of Kid with teachers.)

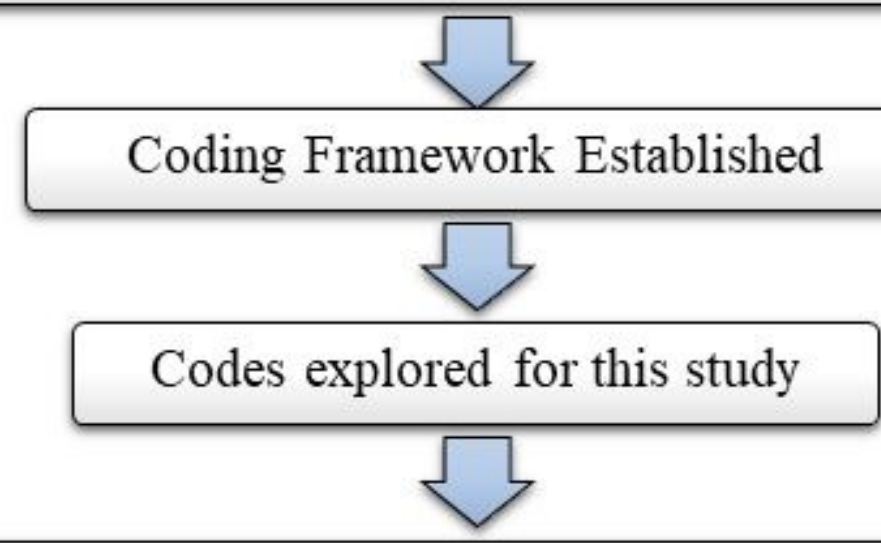

Motivation, interaction and teaching strategy of the teachers

\section{Figure 1}



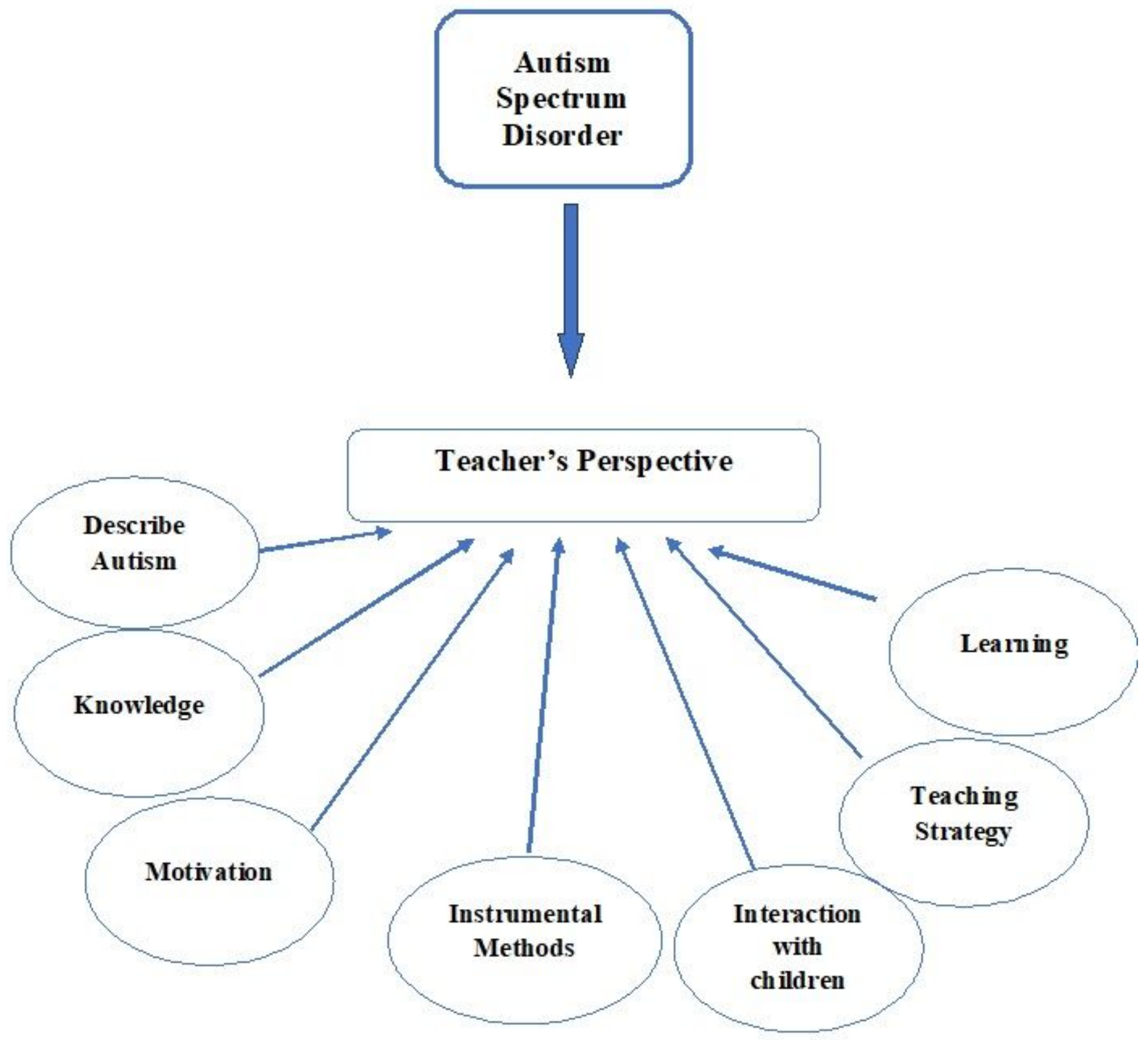

Figure 2

ASD-Teacher's Perspective 


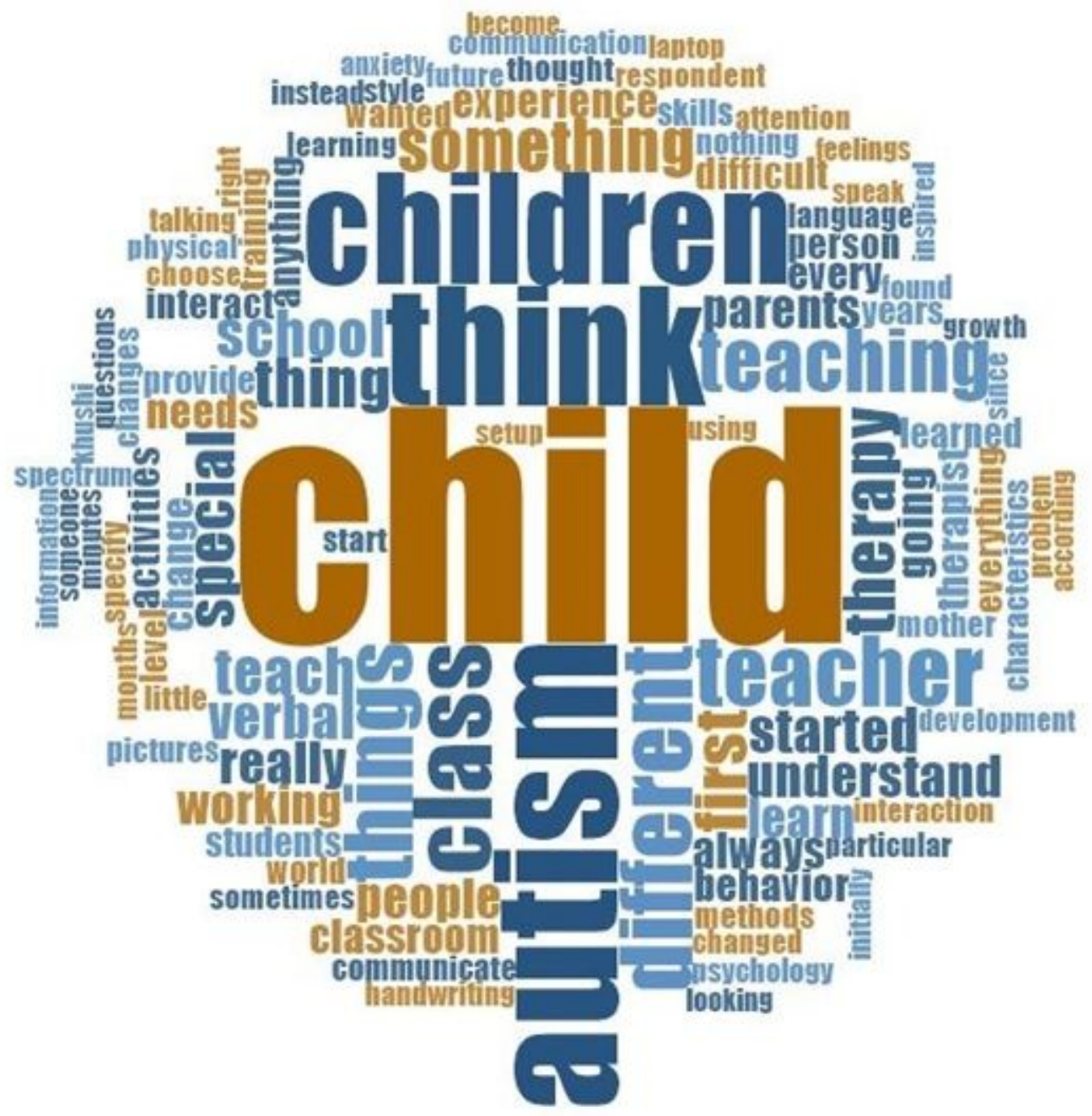

Figure 3

Word Cloud - Teacher's Perspective

\section{Supplementary Files}

This is a list of supplementary files associated with this preprint. Click to download.

- IIPSethicsapproval.pdf 